\title{
Illustrating the Works of Flann O'Brien An Interview with Michael O’Shaughnessy
}

\author{
Michael O'Shaughnessy \\ Liverpool John Moores University
}

The Parish Review: How did you come to illustrate Flann's novels?

Michael O'Shaughnessy: As a recent graduate of an Illustration Course at Manchester Polytechnic back in 1986, I somehow always knew that I would end up illustrating books by Flann O’Brien! In 1995 I was commissioned by Flamingo (an imprint of HarperCollins) to illustrate covers for popular new editions of The Third Policeman, The Poor Mouth, The Hard Life, The Dalkey Archive, Myles Away from Dublin, and The Best of Myles. The commission of these types of books normally involves a number of people: an editor (who answers to an editorial board), an art director, a typographer, a graphic designer, a junior designer, and an illustrator - in this case: me.

TPR: Can you explain a little about the difference between these roles?

MOS: The Flamingo Modern Classics series followed a traditional template: the top third of the cover would have the title plus the name of the author - that was the typographer's domain. The art director gives the illustrator a grid specification and size dimensions to adhere to; apart from that, the content and the context were up to me.

TPR: Were you already a fan?

MOS: I had read The Third Policeman and was already really familiar to some extent with O'Brien's work.

TPR: How did you go about the process?

MOS: The first text I approached was The Third Policeman. As is normal practice in the field, I was given three weeks to come up with an idea for a visual. These images are called 'pencils' or 'roughs' and tend to be fairly basic sketches. I brought these to the art director, who in turn (and after agreement on the basic premise) presented them at an editorial board meeting. If the idea gets the green light (as it did in this case), the illustrator can set to work to produce the finished image for incorporation into the overall cover design.

I approached it from two perspectives: each design was to have a focal point based on a number of male characters. I also included a detail from the narrative on the reverse and tried to give the top section my idea of a rolling Irish sky. The shift in cloud direction would change for each book. 
The Parish Review: Journal of Flann O’Brien Studies 2.2. (Spring 2014)

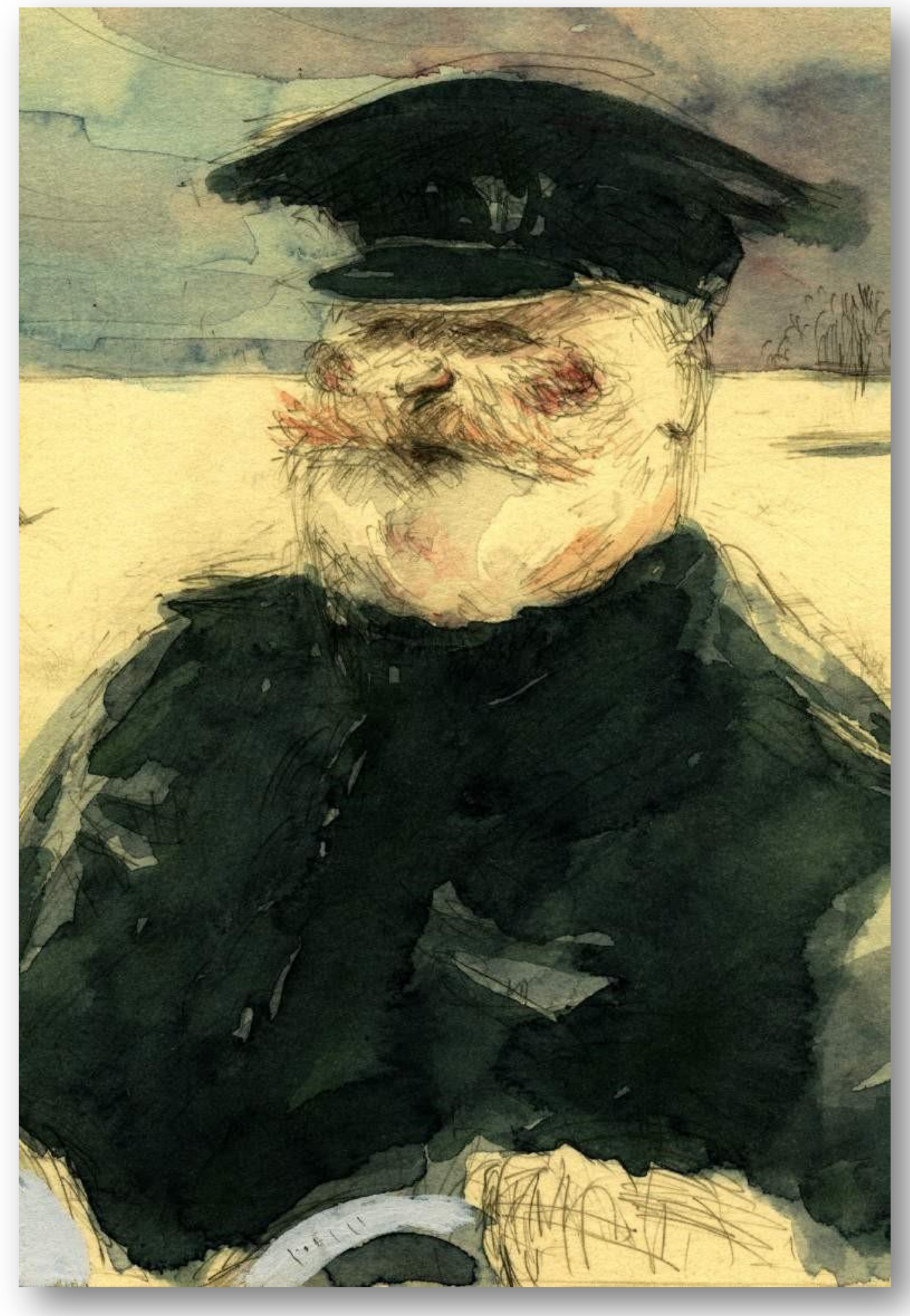

Draft artwork for The Third Policeman

Michael O'Shaughnessy 
TPR: The covers are very distinctive, and I think many people now associate their style with Flann's work - can you give us an idea of what influenced this style?

MOS: My father is a Liverpool Irish musician and I spent a lot of time as a young boy in pubs in the city listening to him playing. There is a certain look that heavy drinkers have, subtle facial details, and I wanted to try to convey this when I was drawing the characters.

The drawing style itself was also highly influenced by the work of the great French caricaturist and satirist Honoré Daumier.

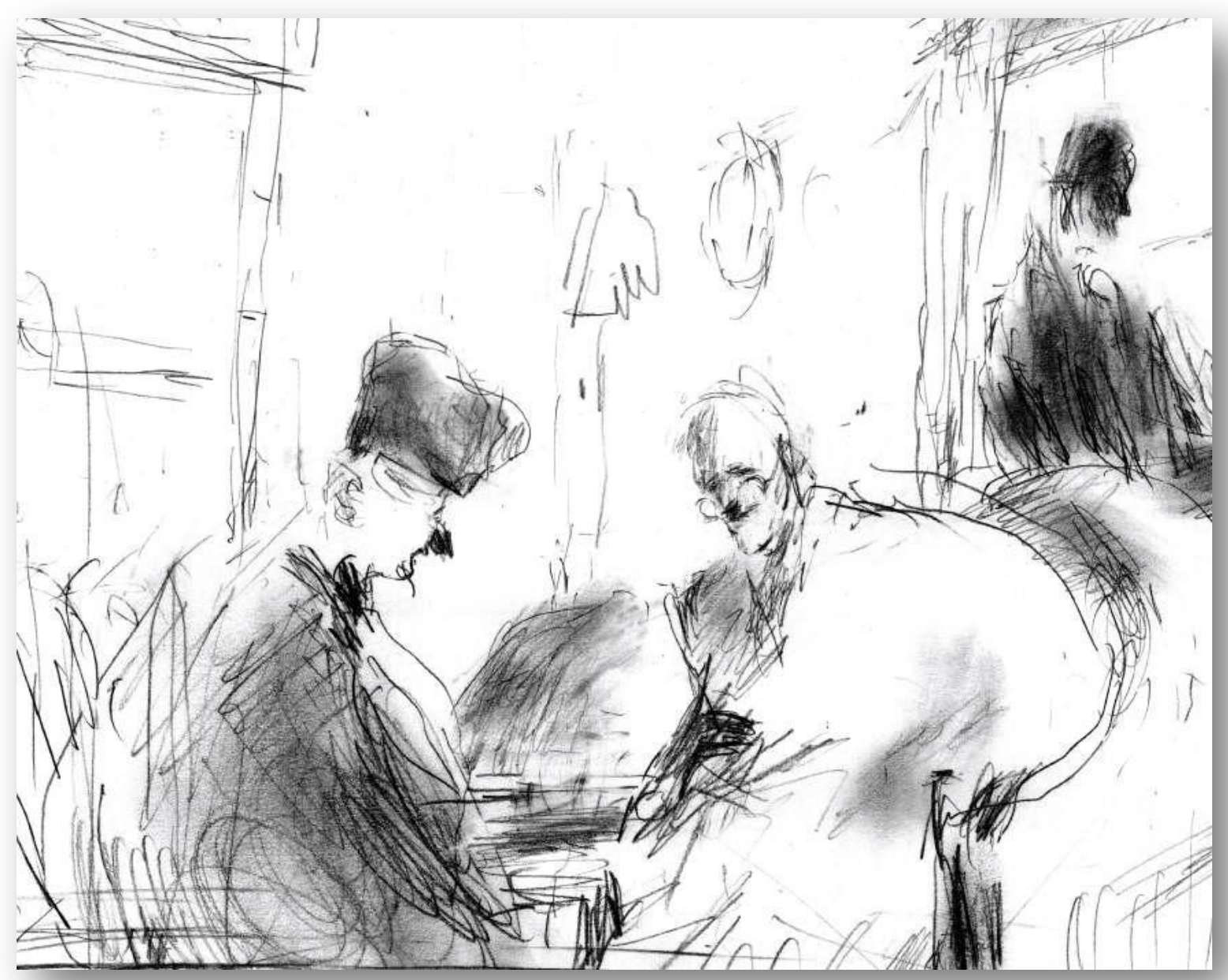

\section{Draft artwork for The Dalkey Archive}

Michael O'Shaughnessy

TPR: Thanks Michael for your time, and for the wonderful illustrations.

Michael O'Shaughnessy is Senior Lecturer in Graphic Design E Illustration at Liverpool John Moores University 